Faletehan Health Journal, 5 (2) (2018) 69-76

www. journal.Ippm-stikesfa.ac.id

ISSN 2088-673X| e-ISSN 2597-8667

\title{
The Effectiveness of High Fidelity Simulation Towards Knowledge and Skills in Health Education: Literature Review
}

\author{
Chiyar Edison S. ${ }^{{ }^{*}}$ \\ ${ }^{1}$ Faculty of Nursing,Universitas Indonesia, Depok , Indonesia \\ $*$ Corresponding Author: chiyar.edison@gmail.com
}

\begin{abstract}
High Fidelity Simulation (HFS) has been recently deemed an effective approach to resemble the real clinical situation so that the improvement of knowledge and skill of student are much more significant. However, there has been much debate in recent times whether this method is much more effective than conventional simulation. This literature review aimed to present the evidence supporting of the effectiveness of HFS especially in enhancing knowledge and skill of health care student. Search terms including "high fidelity simulation", "knowledge" and "skill" were processed into CINAHL, PubMed and Bristish Nursing Index. All papers that published after 2005 and primary research were included. There were totally 9 papers included in this review, as a result of back chaining method involved in searching strategy. This review suggests that HFS is able to improve skill and knowledge of student effectively.

Keywords: High Fidelity Simulation, knowledge, skill
\end{abstract}




\section{Introduction}

Preparing advanced knowledge and skills in healthcare is currently one of the main challenges for health education. This leads to the demand of appropriate teaching strategies to promote student's clinical competence and critical thinking skills (Decker et al, 2008). Simulation is one of the approaches that could lead healthcare students to construct their knowledge and skills comprehensively within complex clinical situations. This educational tool offers some benefits, such as minimum risk of being harmful for patients and learners, high variation of clinical situations, student's clinical experience that can be undergone in non-clinical area, and large opportunities for participants to deepen their knowledge and improve psychomotor skills in a safe environment (Gaba 2004; Gordon and Buckley 2009). Several types of simulations (static manikins, case studies, role-playing, and task trainers) have been utilized over decades to conduct nursing training and education (Smith and Roehrs, 2009).

However, these conventional simulations often only provide students with a limited insight into real clinical experience (Seropian et al, 2003). Therefore, in recent years High Fidelity Simulation (HFS) has been popularly included in education programme in order to resemble clinical practice within educational settings (Leonard et al. 2010). Seropian et al (2003) explicates that HFS does not only provide a realistic appearance but also a realistic reaction so that students can perform their intervention closer to what they might actually face in the actual practice. In addition, HFS utilization offers participants the opportunity to be involved in clinical decision making, practice their skills and observe the outcomes from clinical decisions (Brannan et al. 2008). Yet, as the advanced technology costs billions of dollars, cost is expected to be the main consideration to use it (Hanberg et al, 2005).

Although there are some cost-related issues in using HFS within academic settings, its essential impacts toward the effectiveness of learning process has led the use of this HFS in health education to increase. Several studies have been carried out to prove that elucidated HFS improves responding time intervention, confidence, cognitive and psychomotor skills as well as promotes the development of student's clinical judgment (Hoffman et al. 2007; Howard, 2007; Lasaster, 2007; Brannan et al. 2007; Campbell et al, 2008; Gordon and Buckley, 2009). However, a few studies also find that HFS has no profound effects toward either knowledge acquisition or skill performance (Cherry et al 2006; Jones et al 2011). It is worth noted that in all those literatures, there are various methods and measurement techniques adopted. Therefore, a discussion of several examples from literatures to deeper analyse HFS study is necessary, in particular its effects toward both knowledge acquisition and skill performance.

This literature review aims to determine the effectiveness, if any, of HFS towards knowledge acquisition and skill performance of healthcare students. The primary terminology that will be used in this literature review is High Fidelity Simulation (HFS).High Fidelity Simulation refers to a simulation experience gained from a simulator or a manikin that can be accessed and manipulated with computer system to produce a realistic way in student intervention and control outward appearance (Seropianet al. 2003; Laschinger et al. 2008). Additionally, there will be two main terms to be discussed, knowledge acquisition and skill performance.

\section{Methodology/Searching Strategy}

Literature seacrhing was undertaken in December 2013. This literature review began from searching references on Cumulative Index to Nursing and Allied Health Literature (CINAHL), Medline and British Nursing Index (BNI) using the search terms "High Fidelity Simulation" and "Knowledge" and "Skill". The inclusion criteriaincludes article published after 2005 and primary research. This strategy yielded a total of 61 articles (Table1). However, subsequent effort by identifying the title and abstract based on inclusion criteria resulted in a fewer number of relevant literatures. Therefore, back chaining method was adopted to support the searching strategy, which produced more appropriate articles.

\section{Result and Discussion}

In this back chaining process, article searching by Google Scholar and recommendation articles by Science Direct contributed to find additional articles. Ultimately, there are 9 eligible 
Faletehan Health Journal, 5 (2) (2018) 69-76

https://journal.Ippm-stikesfa.ac.id

ISSN 2088-673X | 2597-8667

articles to be discussed in this literature review(Table 2)

\section{Knowledge acquisition}

Knowledge is an essential learning outcome within health education. This element ought to be possessed in every health care provider as the main component of competence. The use of high fidelity simulation is one teaching method that has the capability to enhance the knowledge gaining in students.

In one study, Brannan et al (2007) conducted quasi-experimental study involving 107 junior nursing students. This research aimed to compare the effects of traditional methods and high-fidelity human-patient simulator in teaching Acute Myocard Infarct (AMI), towards cognitive skill and confidence level. The content of AMI included diagnostic evaluation, pathogenesis and prevention, nursing care during the acute phase as well as nursing care during recovery. According to the objective, Randomised Controlled Trial (RCT) could have been the most appropriate design. However, in this study, the students were not feasible to be assigned randomly due to the academic setting matter. Therefore, quasi experiment study was opted to be an alternative design (Parahoo, 2011, pp.227).

Brannan et al (2007) used Acute Myocardial Infarction Questionnaire (AMIQ) as the measuring tool to assess knowledge acquisition in pre and post test. In the following activity which included a traditional lecture (control group) for two hours and human-patient simulator with a scenario (experimental group), students were given the same AMIQ to be completed. The result indicated that HFS produced some improvement in the AMI knowledge among students.

However, Brannan et al (2007) did not provide detailed information regarding the content of vignette that was involved in human-patient simulator. This study case should have been written to link up with the features of simulator and $A M I Q$, in order to optimise the measuring of the effectiveness of human-patient simulator as an effective teaching method (Cherry et al, 2007). Therefore, despite educator and cardiology expert has been involved and pilot study has been conducted to assess AMIQ, the realibility and the validity of this study is still arguable.

The same result was also found by Hoffmann et al (2007), who studied quasi experiment method with data collected from 29 senior baccalaureate nursing students. It must be acknowledged that the sample size is too small for this type of study. Consequently, it may influence significantly to data generalisability.

Hoffmann et al (2007) conducted pre and post tests using Basic Knowledge Assessment Tool-6 (BKAT-6), which is often utilized to assess the basic knowledge in critical areas for registered nurse prior entering critical care setting. However, Hoffmann et al (2007) applied different approaches to evaluate the knowledgeattainment within students, particularly in terms of the post test timing. BKAT-6 was administered to students three months after the base line, whereas Brannan et al (2007) carried out the post test immediately following the simulation.

Hoffmann et al, (2007) seemingly aimed to see not only the effectiveness HFS in enhancing knowledge gaining, but also how far the students can maintain the knowledge in three months after participating in the simulation. However, the post test ought to be conducted promptly after simulation in order to anticipate some external factors, which may affect the knowledge attainment (Howard, 2007).Regarding this confusion, Hoffmann et al (2007) should present a clear operational definition in order to distinguish various terms, such as knowledge acquisition, knowledge retention, short term knowledge and long term knowledge so that the readers can specifically identify which particulate that would be measured.

Experimental design is not the only way to answer the inquiry of HFS's effectiveness in health pedagogy. Student as an HFS user is an alternative source by obtaining their experience when they are exposed by a simulation. Hence qualitative study, which enables us to understand perceptions and actions of the participants, is an alternative approach (Parohoo 2006, pp. 63).

Table.1 Results of refined literature research

\begin{tabular}{ccc}
\hline $\begin{array}{c}\text { Data } \\
\text { base }\end{array}$ & Term used & Results \\
\hline BNI & $\begin{array}{c}\text { High fidelity simulation } \\
\text { AND knowledge AND skill }\end{array}$ & 10 \\
\hline Pubmed & $\begin{array}{c}\text { High fidelity simulation } \\
\text { AND knowledge AND skill }\end{array}$ & 30 \\
\hline CINAHL & $\begin{array}{c}\text { High fidelity simulation } \\
\text { AND knowledge AND skill }\end{array}$ & 21 \\
\hline
\end{tabular}


Lasaster (2007) used phenomenology qualitative study to explore student's experience of using HFS and the effects of experience towards students' development clinical judgement. This method is one of the most popular qualitative studies that focuses on depicting phenomena of individual experiences (Parohoo 2006, pp. 68).She involved 48 junior students who were enrolled in a course that had an HFS experience in their learning programme. In collecting the data, the focus group was activated to explore student's experience with several predetermined questions, which were delivered as prompts to guide a discussion. However, focus group may not be suitable for an interview method with the aim of the research. Focus group is adopted where individuals and interpretations are not of the primary concerns (Rees 2011, pp. 137). Therefore, individual interview is deemed as the most appropriate technique for the study. Moreover, in focus group the researcher may only gain some general information rather than the personal one. This could yield less in-depth interviews, which would cause the rigour of the study to be debatable.

Table 2. Studies investigating the effectiveness of high fidelity simulation

\begin{tabular}{|c|c|c|c|c|c|}
\hline $\begin{array}{l}\text { Author \& } \\
\quad \text { Year }\end{array}$ & $\begin{array}{l}\text { Patient } \\
\text { Group }\end{array}$ & $\begin{array}{l}\text { Sample } \\
\text { size }\end{array}$ & $\begin{array}{l}\text { Research } \\
\text { Approach }\end{array}$ & $\begin{array}{c}\text { Data } \\
\text { collection } \\
\text { tool }\end{array}$ & Findings \\
\hline $\begin{array}{l}\text { Morgan, P. } \\
\text { J et al } \\
2006\end{array}$ & $\begin{array}{l}\text { Undergraduate } \\
\text { students }\end{array}$ & 299 & quantitative & MCQ & $\begin{array}{l}\text { The was a significant in skill } \\
\text { performance }\end{array}$ \\
\hline $\begin{array}{l}\text { Morgan, P. } \\
\text { J et al } \\
2009\end{array}$ & Anesthethic & 74 & RCT & $\begin{array}{l}\text { Global } \\
\text { Rating } \\
\text { Scale } \\
\text { (GRS) }\end{array}$ & $\begin{array}{l}\text { There was a improvement in skill } \\
\text { performance }\end{array}$ \\
\hline $\begin{array}{l}\text { Gordon \& } \\
\text { Buckley } \\
2009\end{array}$ & $\begin{array}{l}\text { Graduate } \\
\text { medical- } \\
\text { surgical } \\
\text { student }\end{array}$ & 50 & RCT & $\begin{array}{l}\text { Questionna } \\
\text { ire (pre-test } \\
\text { and post- } \\
\text { test) }\end{array}$ & \begin{tabular}{llr}
\multicolumn{2}{l}{ perceivedtechnical } & and \\
nontechnical skills during \\
patientclinical emergencies are \\
enhanced
\end{tabular} \\
\hline Croft 2006 & $\begin{array}{l}\text { Doctors and } \\
\text { midwives }\end{array}$ & 132 & RCT & Videotaped & $\begin{array}{l}\text { Training with HFS associated with } \\
\text { higer deliverr rates. }\end{array}$ \\
\hline $\begin{array}{l}\text { Cherry } \\
2006\end{array}$ & $\begin{array}{ll}\text { First } & \text { year } \\
\text { resident }\end{array}$ & 44 & RCT & MCQ & $\begin{array}{l}\text { Not significant on psychometric } \\
\text { testing but advantage on decision } \\
\text { making skill }\end{array}$ \\
\hline $\begin{array}{l}\text { Brannan et } \\
\text { al } 2007\end{array}$ & $\begin{array}{l}\text { Undergraduate } \\
\text { nursing } \\
\text { student }\end{array}$ & 114 & $\begin{array}{l}\text { Quasie } \\
\text { experimental }\end{array}$ & $\begin{array}{l}\text { Questionna } \\
\text { ire }\end{array}$ & $\begin{array}{l}\text { Positive on ability of answering } \\
\text { question, but noy confidence }\end{array}$ \\
\hline $\begin{array}{l}\text { Lasaster } \\
2005\end{array}$ & $\begin{array}{l}\text { Undergraduate } \\
\text { nursing } \\
\text { student }\end{array}$ & 39 & qualitative & $\begin{array}{l}\text { Focus } \\
\text { group }\end{array}$ & $\begin{array}{l}\begin{array}{l}\text { potential to support } \\
\text { judgment }\end{array} \\
\text { clinical }\end{array}$ \\
\hline $\begin{array}{l}\text { Hofmann, } \\
\text { R.L et al } \\
2007\end{array}$ & $\begin{array}{l}\text { Undergraduate } \\
\text { nursing } \\
\text { students } \\
\end{array}$ & 29 & $\begin{array}{l}\text { Quasi } \\
\text { experiment }\end{array}$ & $\begin{array}{l}\text { Questionna } \\
\text { ire (MCQ) }\end{array}$ & $\begin{array}{l}\text { a significant improvement of } \\
\text { knowledge gaining }\end{array}$ \\
\hline $\begin{array}{ll}\text { Jones, } & \text { T. } \\
\text { L, et al } & \\
2011\end{array}$ & $\begin{array}{ll}\text { Third year } \\
\text { nursing } \\
\text { students }\end{array}$ & 84 & $\begin{array}{l}\text { Quasi } \\
\text { experiment }\end{array}$ & $\begin{array}{l}\text { Questionna } \\
\text { ire (MCQ) }\end{array}$ & $\begin{array}{l}\text { no significant different knowledge } \\
\text { score between medium fidelity } \\
\text { simulation and HFS. }\end{array}$ \\
\hline
\end{tabular}


Faletehan Health Journal, 5 (2) (2018) 69-76

https://journal.Ippm-stikesfa.ac.id

ISSN 2088-673X | 2597-8667

Lasaster (2007) reported a finding in which most students commented that HFS was able to provide integration learning by combining theoretical basis from their class and books, as well clinical skills from laboratory teaching and clinical practice. This advantage led students to critically think in responding to the scenario given. Although the improvement in gaining knowledge was not mentioned by students, it may be concluded that HFS provided opportunities for students to enhance their clinical judgment development.

Apart from the finding mentioned previously, a few studies show noticeably different results about the effects of HFS. In RCT design, Cherry et al (2006) randomized 44 resident students who were enrolled in Advanced Trauma Life Support (ATLS) course into control group (traditional teaching) and experimental group (HFS). By using MCQ as the assessment to evaluate the influence of HFS to cognitive skill, the result indicated that there was no significantly score difference between students in control group and experimental group, either in terms of pre and post MCQ tests or the changes in scores. However, this research has a small sample size number, which may limit its generalisability. This weakness can also bring a failure to measure the effectiveness of intervention group (Parahoo 2006, pp. 221). Therefore, Cherry et al (2006) pointed out that the results would not able to demonstrate the practical or essential relevance to be implemented in assessing the whole clinical performance.

By using quasi experiment method, Jones et al (2011) measured knowledge acquisition within 84 third year nursing students who were exposed by medium fidelity simulation and HFS patient manikin. The researchers collected data in three phases, prior to the simulation, immediately following and two weeks after simulation. The data were analysed by using an independent $t$ test and Analysis and Covariance (ANCOVA). The function of the independent $t$ test in quasi experiment study is to compare the means of two different groups (Rees, 2011). ANCOVA was carried out by Jones et al (2011) to identify whether the knowledge score changes appeared while a score improvement was observed. Both test analysis approaches found that there was no significant different knowledge score between students who were exposed medium fidelity simulation and HFS. This result led to a suspicion that the effectiveness of medium fidelity simulation was actually equal to HFS.

However, Jones et al (2011) contended that the result was simply a consequence of using MCQ as an assessment method to measure the effectiveness of simulation experience, which was not appropriate. Measuring tool was acknowledged as a common problem since sometimes they were not sensitive enough to see the small difference between experimental and control group (Parohoo 2006, pp.301).Hence, a further study about the effectiveness of MCQ as a tool to measure the effects of simulation may be necessary.

Even though all these studies do not yield the same agreement regarding the effects of HFS in knowledge gaining, there are two points that can be drawn and worth to be noted. Firstly, to see the effectiveness of HFS to enhance learning outcomes and knowledge retention is another concern that needs to be more valued. Knowledge acquisition tends to be more related to short-term knowledge while knowledge retention is more inclined to long-term knowledge. This issue will determine when the most appropriate time is to carry out the post test following the simulation experience of the students. Furthermore, the measuring tool is an essential aspect to decide how far HFS can give impacts to the knowledge level. There should be an alternative tool to measure higher complex knowledge besides MCQ, which is likely often used because of its convenience. Therefore, the adoption of a more appropriate approach is expected to able to measure the effects of using HFS accurately.

\section{Skill acquisition}

Good skill peformance is a crucial element in heathcare providers, in which represent the competency and knowledge to meet patients' need. Simulation is one of approaches that can provide opportunity for students' in improvinf their skill (Gaba, 2004; Gordon and Buckley, 2009).

Morgan et al (2006) conducted a quantitative study to evaluate 229 undergraduate medical students who were exposed by HFS experience, to see whether the experience improved skill performance. This simulation was assessed by using a performance checklist and a global rating 
scale that had been used by the previous research (Morgan et al. 2004). After the simulation had completed, the facilitator carried out a discussion to provide feedbacks by utilising videotaped performances as the template. This was followed by conducting a post test by using the same MCQ and scenario with pre test. To assess the simulation performance, repeated measured analysis of variance (ANOVA) was used, which resulted in the improvement score $(p<0.0001)$ for both checklist performance and global rating scale.

As the result showed that there was a statistical improvement in the written test and performance, Morgan et al (2006) pointed out that HFS could provide students with a worthwhile learning experience and enable them to make a link between theory and practice. However, control group was not adopted in their study method. This control study group should have been used as a comparison that would assure that the outcomes were only affected by intervention (Parahoo 2006, pp. 221)

Similar finding was also found in a descriptive study that aimed to examine the effects of HFS towards skill performance of 50 medical surgical nursing students in dealing with emergency cases (Gordon and Buckley, 2009). The participants attended the theoretical course for 14 hours to deepen their pre-knowledge related to clinical emergencies. Following this stage, they were engaged to run simulation with one of the scenarios by using HFS. Data were collected by questionnaires, which were completed by students prior to and following the simulation. The data analysis indicated that there was a high confidence level of ability in order to respond patients with clinical emergencies.

However, the validity and reliability of the questionnaires was questionable due to the absence of detailed explanations about tool assessment. Though validity is more challenging to ratify, but at least, reliability can be confirmed by conducting a pilot study prior to carrying out the research (Rees 2011, pp. 26). Furthermore, bias within the sample was seemingly not controlled properly since the previous trainings and experiences of all participants were ignored. Predetermined inclusion and exclusion criteria should have been introduced, as to what characteristics were typical to study group (inclusion) and biased in the group (exclusion) (Rees 2011, pp.26)

These two literatures have found an evidence that skill attainment can be enhanced by involving HFS as a learning tool despite the fact that some limitations must be acknowledged. However, they merely showed the effectiveness of HFS by measuring immediately after simulation was completed.

Croft et al (2006) examined the effectiveness of HFS compared to low fidelity simulation (LFS) in the training of shoulder dystocia management. This RCT study involved 140 participants comprised of 45 doctors and 95 midwives. This sample derived from six hospitals, which had delivery rate ranging from 2,500 to 4600 per annum. Every selected hospital provided the list of eligible staff, which was stratified by staff groups and experiences. Stratified random sampling is one of the sampling methods commonly applied in experimental study when the sample frame consists of units with varied variables (Parahoo 2006, pp.262).

All participants were randomly assigned to control group and experiment group, in which to attend practical workshop in management of shoulder dystocia by using either LFS (control group) or HFS (experiment group). After three weeks, post training assessment was carried out to evaluate the effectiveness HFS and LFS. All activities during training were recorded by video tape recorder. The reviewers had been blinded to pre or post test and the training intervention prior to viewing the video of simulation. This technique is called single blinding, which means either the researchers or the subjects are not notified about the group allocation (Parahoo 2006, pp.235).

According to the result, the training with HFS produced greater successful delivery rate than the one using LFS, 94\% successful participants compared to $72 \%$. This result shows a significant evidence that HFS can improve psychomotor skills needed by midwives and doctors to perform management of shoulder dystocia. However, the participants consisting of midwives and doctors were generally divided into two categories: seniors and juniors according to their experiences. The difference of professional educational background may influence the learning ability of each participant, a variable which is difficult to be controlled (Parahoo 2006, pp.237). 
Faletehan Health Journal, 5 (2) (2018) 69-76 https://journal.Ippm-stikesfa.ac.id ISSN 2088-673X| 2597-8667

In another study, Morgan et al (2009) carried our RCT study to determine whether HFS exposure enhanced the performance of practising anaesthetists in managing a particular clinical scenario. After participants signed up consent forms, 74 anaesthetists were randomly allocated to group A (simulation debriefing), group B (home study) and group $\mathrm{C}$ (no intervention). Beside the part of ethical consideration, in RCT, consent form is aimed to ensure participants would be well informed that they cannot choose which group they want (Parahoo 2006, 245). The participants ran their assigned scenario to perform a simulation of anaesthetist management. This pre-test was assessed by dichotomously scored list and global rating scale (GRS) that had been used in the previous study (Morgan et al, 2007). After six to nine months, participants returned to complete the post test by performing the exact same scenario in simulating the case management. The result indicated that HFS improved skill attainment and retention. However, in this study, there was no effort from researchers to control the participant from another factor that can influence the impact of HFS during six to nine months prior to the post test. This limitation reflected the issue of internal validity in RCT, which is refer to the ability of research to ensure only the indepedent variable that has influenced to dependent variable changing (Parahoo 2006, pp.236 ; Rees 2011, pp. 233)

To sum up, all studies have found the evidence that HFS has the capability to improve skill performance, either in short term or long term. However, the main challenge of researchers is how to guarantee that HFS is the only impact contributor to improve the skill performance. Moreover, the type of tool assessment to measure skill is also an issue that has to be explored in further

\section{Conclusion}

This literature review shows that the engagement of HFS in learning process can generally promote the improvement of knowledge and skill acquisition. However, several studies as mentioned above found that the use of HFS did not bring the expected impacts to the learning outcomes. There are still some considerations that this technology would not be the most appropriate teaching tool as their cost causes an issue as well.
The clear positive evidence that has been found, however, cannot be ignored.

As a result, the use of HFS in heath education cannot replace the conventional teaching method. HFS indeed has the capability to enhance knowledge and skill acquisition, yet health educators would need to pay scrupulous attention to matching the teaching tools with the objectives of learning.

Despite several studies that have been carried out to reveal the effectiveness of HFS on students' knowledge and skill acquisition, health pedagogy may require further works to gain more various approaches. One occurrence that should be remarked is the use of MCQ as a tool to measure knowledge acquisition. MCQ is indeed a wellknown tool assessment because of its convenience to be utilised. However, higher-level knowledge such as clinical decision-making skill would require an alternative variety of tools to be able to measure more accurately and reduce the risk of biased results. Hence, MCQ ought not to be considered as the only type of knowledge assessor.

Furthermore,most studies have been carried out in quantitative approach rather than qualitative. Students' experience should be more explored to obtain different angles about the effects of HFS. In other words, the number of qualitative study is proposed to be enhanced.

\section{Reference}

Brannan, J. D., White, A., \&Bezanson, J. L. (2008).Simulator effects on cognitive skills and confidence levels.Journal of Nursing Education, 47(11), 495-500.

Campbell, D. M. et al. (2009). High Fidelity Simulation In Neonatal Resuscitation. Pediatric Child Health, 14, pp. 19-23.

Cherry, R. A., Williams, J., George, J., \& Ali, J. (2007). The effectiveness of a human patient simulator in the ATLS shock skills station. Journal of Surgical Research, 139(2), 229235

Crofts, J. F., Bartlett, C., Ellis, D., Hunt, L. P., Fox, R., \& Draycott, T. J. (2006). Training for shoulder dystocia: a trial of simulation using low-fidelity and high-fidelity mannequins. Obstetrics \& Gynecology, 108(6), 1477-1485.

Decker, S., Sportsman, S., Puetz, L., \& Billings, L. (2008). The evolution of simulation and its 
contribution to competency. The Journal of Continuing Education in Nursing, 39(2), 7480.Linda, O. (2011). Huungan Peendidikan dan Pekerjaan Orang Tua Serta Pola Asuh Dengan Status Gizi Balita Di Kota dan Kabupaten Tangerang, Banten. 137.

Gaba, D. M. (2004). The future vision of simulation in health care. BMJ Quality \& Safety, 13(suppl 1), i2-i10

Gordon, C. J., \& Buckley, T. (2009). The effect of high-fidelity simulation training on medicalsurgical graduate nurses' perceived ability to respond to patient clinical emergencies. The Journal of Continuing Education in Nursing, 40(11), 491-498.

Hanberg, A., Brown, S. C., Hoadley, T., Smith, S., \& Courtney, B. (2007). Finding funding: The nurses' guide to simulation success. Clinical Simulation in Nursing, 3(1), e5-e9.

Hoffmann, R. L., O'donnell, J. M., \& Kim, Y. (2007). The effects of human patient simulators on basic knowledge in critical care nursing with undergraduate senior baccalaureate nursing students. Simulation in Healthcare, 2(2), 110-114.

Howard, V. M. (2007). A comparison of educational strategies for the acquisition of medical-surgical nursing knowledge and critical thinking skills: Human patient simulator vs. the interactive case study approach (Doctoral dissertation, University of Pittsburgh).

Levett-Jones, T., Lapkin, S., Hoffman, K., Arthur, C., \& Roche, J. (2011). Examining the impact of high and medium fidelity simulation experiences on nursing students' knowledge acquisition. Nurse education in practice, 11(6), 380-383.
Laschinger, S., Medves, J., Pulling, C., McGraw, D. R., Waytuck, B., Harrison, M. B., \& Gambeta, K. (2008). Effectiveness of simulation on health profession students' knowledge, skills, confidence and satisfaction. International Journal of Evidence-Based Healthcare, 6(3), 278-302.

Leonard, B., Shuhaibar, E. L., \& Chen, R. (2010). Nursing student perceptions of intraprofessional team education using highfidelity simulation. Journal of Nursing Education, 49(11), 628-631.

Morgan, P. J. et al. (2006). Applying Theory To Practice in Undergraduate Education Using High Fidelity Simulation. Medical Teacher, 28 (1), e10-e15

Morgan, P. J. et al. (2009). Efficacy Of High Fidelity Simulation Debriefing On The Performance Of Practicing Anaesthetist In Simulated Scenarios.British Journal of Anaesthesia, 103(4), 531-537.

Parahoo, K. (2014). Nursing research: principles, process and issues. Macmillan International Higher Education

Rees, C. (2011). Introduction To Research For Midwives. UK : Elsevier Ltd.

Seropian, M. A., et al. (2004). Simulation: Not just a manikin. Journal of Nursing Education, 43(4), 164-169.

Smith, S. J., \& Roehrs, C. J. (2009). High-fidelity simulation: Factors correlated with nursing student satisfaction and self-confidence. Nursing Education Perspectives, 30(2), 74 78. 